DOI: $10.1515 /$ abcsj-2014-0028

\title{
Performing Arabness in Arab American Stand-up Comedy
}

YASSER FOUAD SELIM

\author{
Sohag University
}

\begin{abstract}
This article deals with the dramatic art of stand-up comedy. It locates Arab American stand-up comedy within a broader American humorous tradition and investigates the way Arab American performers use this art to negotiate and (re)construct their identity. The main question in this article is the way Arab American stand-up comedians define their relationship to the Arab and the western worlds in the process of establishing their Arab American identity. Three humor theories - the relief theory, the incongruity theory, and the superiority theory - are deployed in the study to examine the representation of Arabness in selected Arab American performances. The study argues that Arab American comics minstrelize their own diasporic origin through reinscribing a range of orientalizing practices in order to claim their Americanness.
\end{abstract}

Keywords: Arab American, stand-up comedy, Maysoon Zayid, Ahmed Ahmed, Dean Obeidallah, Aron Kader, humor, identity

The art of stand-up comedy is one of the most scholarly marginalized theatrical forms. There is very little academic and scholarly attention given to the study and analysis of stand-up comedy despite its old history and present popularity. Arab American stand-up comedy is the most marginalized in the tradition. This article is an attempt to fill a gap in the study of stand-up comedy in general and the criticism of Arab American artistic expression in particular. The article starts with defining stand-up comedy and tracing its historical connection to the negotiation and projection of ethnicity. The study, then, deploys three humor theories: the relief theory, the incongruity theory, and the superiority theory, with a 
view to examining the performance of Arabness in selected Arab American stand-up routines. Performances of four Arab American standup comedians - Ahmed Ahmed, Dean Obeidallah, Maysoon Zayid, and Aron Kader - are selected to explain how the Arab American identity is negotiated and construed in relation to Arabness and Americanness. The analysis is based on transcriptions of performances posted on YouTube.

Stand-up comedy is a kind of dramatic performance that takes place on a stage where a performer gives improvised or scripted humorous monologues before live audiences. Stand-up comedy is often shortened to "stand-up." According to the Merriam Webster dictionary, "stand-up" is "a monologue of jokes, gags, or satirical comments delivered usually while standing alone on a stage or in front of a camera." Categorizing stand-up under a literary genre, Ian Brodie calls it a "verbal play ... [that] utilises humour" (154). American professor Laurence E. Mintz gives a more comprehensive definition of the term in his insightful article "Standup Comedy as Social and Cultural Meditation." He explains:

A strict limiting definition of stand-up comedy would describe an encounter between a single, standing performer behaving comically and/or saying funny things directly to an audience, unsupported by very much in the way of costume, prop, setting, or dramatic device. Yet stand-up comedy art's roots are ... entwined with rites, rituals, and dramatic experiences that are richer, more complex than this simple definition can embrace. (71)

In his $\mathrm{PhD}$ dissertation "Laughter in Revolt: Race, Ethnicity, and Identity in the Construction of Stand-up Comedy," Mathew Daube defines stand-up comedy as a dramatic work in which "the number of players is reduced to one, who performs his or her own character, complete with name and life history" (5). It could be argued that stand-up comedy is a play in which the comedian is the writer, actor, and character of his or her own dramatic performance. It could also be argued that stand-up is more authentic than any other form of theatrical performance because it offers on-stage autobiographical oral narratives that question identity and culture of both the self and the other. Juan Sjobohm affirms that "a comedian performing the repertoire of another comedian is uncommon, if not existent, in the context of stand-up" because using somebody else's stories 
in stand-up comedy is considered "plagiarism" (5). Stand-up is unique in offering acerbic social and cultural critique of the self and the other and at the same time it escapes the censor through its "comic license." In standup comedy, performers and producers can approve the show on the basis that "it is just a joke," as Paul Mcllvenny, Sari Mettovaara, and Ritva Tapio remark:

One reason for the critical place of humour in western societies, and maybe in all human societies is that it escapes the censor, thus allowing a "dangerous" use and abuse of convention. But the danger can be diffused because the humorous mode separated from the realm of serious discourse enables performers to deny the import of a humorous remark by claiming it was only a joke. (227)

Mintz proclaims that stand-up comedy, although undervalued by critics and researchers when compared to humorous and serious literature, is "the oldest, most universal, basic, and deeply significant form of humorous expression" (71). He traces the art to the Middle Ages jester and clown performances which took the form of donning colorful clothes and performing humorous actions with a variety of acrobatics, comedy, music, and magic to entertain the king and the nobility. However, the closest art to modern day stand-up comedy could be seen in nineteenthcentury minstrelsy. From the early years of the 1800s until the few decades following the Civil War, blackface minstrelsy was very popular in the U.S. White performers used to don black faces to entertain white audiences through mocking black people and staging stereotypical negative images of the African American culture. Jerry Zolten, associate professor of Communication Arts \& Sciences and American Studies at Penn State Altoona, says, "Minstrelsy was . . . a source for much of the stereotype that still lingers today about African Americans, a group more maligned in the name of entertainment than any other" (qtd. in Parker). In these minstrel shows, white performers employed what was called a "stump speech" in which they stood atop a tree stump and parodied black people vernacular while giving commentary on social and political taboos.

By the late $19^{\text {th }}$ century, the minstrel shows gave place to the art of vaudeville which was less concerned with racial satire. The vaudevilles did not target the vilification of races. They were more about laughing at 
people's differences. The art was called "polite vaudeville or refined vaudeville" because its main target was to "provide a respectable and decent entertainment that families could patronize without damage to their reputations" (Cullen 18). The advent of the Roaring 1920s and the invention of the radio and microphones provided vaudeville artists with unprecedented opportunities to broadcast their humor and reach out to American automobiles and houses. Zoltan explains that the patriotism spirit during the war pushed the American comedians further to center their monologues on "poking fun at what we [Americans] as a society could all laugh at together" rather than mocking and laughing at one another (qtd. in Parker).

After the war was over and amidst the Civil Rights period, when the relationship between the ethnic individual's heritage and Americanness was of high concern, a number of comedians started questioning American social, religious, ethnic, and political norms. Mathew Daube argues that comedians like Lenny Bruce, David Gregory, Bill Cosby, and Richard Pryor "were the vanguard of those who altered the older traditions of comic joke-telling into an extended direct conversation with the audience, creating a space of extraordinary intimacy" (1). Daube's selection of Jewish and African American artists to study the construction of stand-up comedy in the U.S. proves his argument that "stand-up's style and subject are intractably linked to issues of race, ethnicity and the production of identity. Arising in the midst of the Civil Rights era, the form lent itself to racial and ethnic minorities who queried the evolving relationship between the individual and the society-as-a-whole" (1).

In his Stand-up Comedy in Theory, or, Abjection in America, the first study of stand-up comedy as a form of art, John Limon states that in the 1950 s and 1960 s, the profession was dominated by "Jewish, male, heterosexual comedians" and that it paradoxically lent itself recently to "female, homosexual, black, Christianizing" comedians (6). I suspect Limon would have made mention of Arab American stand-up comedy if he had written his book after 2001. Arab American literature and arts have often been ignored in the American literary and artistic scenes, and standup comedy is no exception. After September 11, 2001, Arab Americans discovered the value of the humorous art of stand-up in tackling issues of 
race, ethnicity, and identity. If early American stand-up comedy rose out of the Civil Rights era and the minorities' quest for recognition in America, Arab American stand-up comedy appeared after the traumatic experience of 9/11 to question the Arab American identity and its location within the American mosaic.

The question of defining the Arab-American identity in relation to the Arab and American parts that precede and follow the hyphen is what is going to be investigated in the remainder of this article. The three theories of humor utilized in this analysis - the relief theory, the incongruity theory and the superiority theory - are often regarded to be the basic and central theories that explicate the function and mechanism of humor. Although there are tens of studies that validate or refute these different theories against one another, the three hypotheses are more compatible than different and can be safely deployed simultaneously to explain one humorous expression.

According to the relief theory, one of the major functions of humor is to reduce stress. In "The Physiology of Laughter," Herbert Spencer argues that laughter is a physiological process in which "quasi-convulsive contractions of the muscles" result from "an uncontrolled discharge of energy" (7566). Humor, according to Spencer, is a way through which nerve centers of tension discharge themselves. This relief aspect of humor is highlighted by many philosophers, physiologists and psychologists including Alexander Bain (The Emotion and the Will 1859), Anthony Ashley Cooper, Earl of Shaftesbury (An Essay on the Freedom of Wit and Humour 1971), and Sigmund Freud ("Humour" 1927). Freud is often regarded as making the strongest statement about humor from a psychological perspective. He argues that humor has a "rebellious" (163) nature in the way it challenges negative energy and helps overcome distress and socio-cultural restrictions. He concludes:

The grandeur in it [humour] clearly lies in the triumph of narcissism, the victorious assertion of the ego's invulnerability. The ego refuses to be distressed by the provocations of reality, to let itself be compelled to suffer. It insists that it cannot be affected by the traumas of the external world; it shows, in fact, that such traumas are no more than occasions for it to gain pleasure. This last feature is a quite essential element of humour. (162) 
The post-9/11 trauma of Arab Americans was very distressing. Arab Americans had to confront their stigmatization and the accusations of being culturally different and dangerous. They soon rediscovered standup comedy and the ability of humor to alleviate dejection and relieve tension and stress. In 2003, the Arab American Comedy Festival was founded by Arab American comedians Dean Obeidallah and Maysoon Zayid to build resilience after $9 / 11$ and to reclaim the Arab American identity through performing ethnicity in front of a good number of Arab and Caucasian American audiences attracted to the performances. Commenting on the mission of the Arab American Comedy Festival, Obeidallah says, "We choose to foster understanding, dispel stereotypes, make people understand who we are a little, and define us in a much more accurate way" (Aita). The Egyptian American comedian Ronnie Khalil adds, "After $9 / 11$, there was a lot of negative portrayal of our community in the media. There is still a limited view of who Arabs are, but at least now people are willing to learn more about us" (Salama).

In their stand-up comedy, Arab American comedians turn their distress into humor by mocking their own afflictions. The satisfaction and pleasure found in their performances are not only felt by them but by the audience as well. Freud argues that one way the humorous process takes place is when a single person adopts a humorous attitude while another person derives pleasure from it as a spectator. He mentions the example of a criminal who remarks, as he is going to the gallows on Monday, "Well, the week's beginning nicely" (161). While the humor gives sort of satisfaction to the criminal, it also gives the listener the same sense of humorous pleasure. Both the criminal and the listener overcome the stress created by the execution moment and experience relaxation and relief. Freud elaborates this "gallows humor" by saying:

He [the spectator] sees this other person in a situation which leads the listener to expect that the other will produce the signs of an affect - that he will get angry, complain, express pain, be frightened or horrified or perhaps even in despair; and the onlooker or listener is prepared to follow his lead and to call up the same emotional impulses in himself. But this emotional expectancy is disappointed; the other person expresses no 
affect, but makes a jest. The expenditure on feeling that is economized turns into humorous pleasure in the listener. (161-162)

In stand-up comedy, sharing initial despair and finally experiencing humorous pleasure create unity and understating between the performer and the audience. In the case of Arab American stand-up, the performer is the stereotyped and the spectator is the stereotyper. The stand-up humor reorders the relationship between them and creates a sense of camaraderie, instead of prejudice, which is one of the basic functions of humor as stated by Mintz: "The structure of jokes tends to be subversive; in other words, jokes tear down, distort, misrepresent, and reorder usual patterns of expression and perception" (73).

Let's take one of Ahmed Ahmed's performances as an example of this tension relief function of humor. Ahmed Ahmed, an Egyptian American comedian, is one of the most recognized Arab American standup artists. $\mathrm{He}$ is famous for commencing his performances with a statement of his everlasting, unusual problem: "My name is Ahmed Ahmed, and I can't fly anywhere" ("Stand-up Comedy"). Due to the level of security clearance he must pass, Ahmed jokes that he always has to arrive at the airport ninety minutes before the flight wearing a g-string. The fact that Ahmed Ahmed goes through strict security clearance before he travels is never humorous. However, it is made funny by the performer in order to discharge the negative energy of being othered and to replace this negative energy with pleasant emotions. Fastening his seat belt and getting ready for taking off, somebody approached him and pulled him off the plane. The two American guys sitting next to him exclaimed, "I thought he was a Mexican! We were sitting next to al Qaeda the whole time!" Ahmed answered them in an American accent, "I'll be right back, bitch, just save my seat. I'll be right back. It's Bullshit!" ("Stand-up Comedy"). The punch line of the joke is that the passengers took Ahmed as a terrorist, but he proved them through his American English that he was an innocent American. The despair and anguish over his mistreatment at the airport are mocked and the anger turns into humorous pleasure. This pleasure or "gallows humor," to use Freud's words, is shared by Ahmed Ahmed and the audiences and creates a sense of understanding between them. Laughter creates codes of agreement and reception between the 
comedian and the audience, as incisively explained by Jack G. Shaheen, the author of Reel Bad Arabs:

Historically, humor has always been used to put people at ease and sort of open themselves up to receiving messages that make them aware of their prejudices without offending them .... It's a wonderful way to help shatter stereotypes because with true laughter, particularly in open-minded people, comes real renewal and enlightenment. (qtd. in Marks)

The mechanism of humor in Ahmed Ahmed's performance, as well as in most of the Arab American stand-up comics' routines, derives from an incongruity between what is expected and what is real. The passengers expected Ahmed to be a Mexican and once he was pulled off the plane, they thought he was an Arab terrorist. His answer in American slang suddenly transformed him from a dangerous passenger into an innocent Arab American, which creates humor. The contrast in the situation creates absurdity, and frustration is found to be pleasant when the serious is made trivial. Immanuel Kant explains that incongruity creates humor when " $a$ tense expectation is suddenly transformed into nothing" (203). It is an intellectual recognition of the incongruity between what is expected and what is real. The basic incongruity in Arab American stand-up comedy, in general, is the intellectual recognition of the difference between the expected Arab American and the staged one. The Arab American, who is expected to be a threatening anomalous figure belonging to an alien Arab culture, is actualized on the stage as a funny American speaking unbroken English. In his book The Phantoms in the Brain, V.S. Ramachandran points out that "the main purpose of laughter might be to allow the individual to alert others in the social group (usually kin) that the detected anomaly is trivial, nothing to worry about. The laughing person in effect announces her discovery that there has been a false alarm; that the rest of you chaps need not waste your precious energy and resources responding to a spurious threat" (206).

Moreover, the performances help in creating a sense of unity between the Arab American performer and the spectator. What is very striking in this incongruity is that the trivial anomaly presented by the Arab American performers is the Arab part of the hyphen. In Ahmed 
Ahmed's performance about the airport check, the joke derives not only from the realization that Ahmed is an American citizen but also from the recognition that he is distant from the Arab stereotype. In this performance, Ahmed is in effect saying, I am not a terrorist Arab; I am an innocent Arab American, which makes me more in accord with America than with my Arab origins. His marginalization is presented as rooted in his Arabness, a defect he needs to uproot in order to create a unique Arab American identity that is closer to the Western than the Arab. Mintz's description of the function of stand-up comedy helps to explain this point:

Traditionally, the comedian is defective in some way, but his natural weaknesses generate pity, and more important, exemption from the expectation of normal behavior. He is thus presented to his audience as marginal. Because he is physically and mentally incapable of proper action, we forgive and even bless his "mistakes." (74)

The weak or defective part in the Arab American character, as presented in this particular performance by Ahmed, is the Arab origin. It creates the Arab American marginality and accounts for his pathetic situation within the American social and cultural structure. Ridiculing such a part is a way to reject it and show superiority of the self over it. It is the mistake which, when forgiven by western audiences, might reconstruct the Arab American identity and make it part of the American mosaic.

Actually, most of the humor in the Arab American stand-up performances is based on the superiority theory which proposes that humor is generated at the cost of ridiculing an inferior other in an attempt to show superiority over it. In his Poetics, Aristotle notes that "comedy . . . is an imitation of characters of a lower type. . . It consists in some defect of ugliness which is not painful or destructive. To take an obvious example, the comic mask is ugly and distorted, but does not imply pain" (Butcher 21). Aristotle thinks that we laugh at ugliness because it erects our beauty when compared to it. The inferiority of the ridiculed ugly object instigates malicious enjoyment and joy. English philosopher Thomas Hobbes explains the same idea of the feelings of joy at realizing the inferiority of others in his seventeenth century book Leviathan. Hobbes argues that "sudden glory is the passion which maketh those 
Grimaces called LAUGHTER; and is caused either by some sudden act of their own that pleaseth them; or by the apprehension of some deformed thing in another, by comparison whereof they suddenly applaud themselves" (34). The superiority theory is supported by some other writers like C.R. Gruner (The Game of Humor 1997), Albert Rapp (The Origins of Wit and Humor 1951), and Konrad Lorenz (On Aggression 1963).

This superiority aspect of humor is provided also by Richard D. Alexander in his article "Ostracism and Indirect Reciprocity: The Reproductive Significance of Humor." Alexander argues that "humor is hypothesized to be a social activity that alters the status of the humorist positively and that of the object or victim negatively." He states that humor has an ostracizing function that gives superiority of the humorist over the humorized. Some of the benefits of telling jokes, according to Alexander's hypothesis, are the following:

1. Elevating of one's own status in relation to

a. Part of the group (audience)

b. All of the group (audience)

c. One or more third parties not present

2. Lowering of someone else's (the "victim's") status in relation to one's self

a. The victim is the only individual present

b. The victim is not the only one present

c. The victim is not present.

3. Reinforcing (maintaining) a presumably favorable status relationship with

a. Part of the group (audience)

b. All of the group (audience)

c. One or more third parties not present. (258)

In most of the Arab American stand-up comedies, social ostracism is directed towards one's ancestral roots. The Arab is victimized, while the Arab American's status is elevated and a sense of camaraderie relationship is formed and reinforced between the Arab American comedian and the mainstream audiences. This social ostracism is expressed in different ways by the Arab American stand-up comedians. Verbal scorning of Arabness, ridiculing Arab traditions and values, violating Arab cultural and religious taboos, looking at Arabs with a 
tourist gaze and creating a dichotomy of funny Arab Americans versus stupid Arab terrorists - are all examples of the different techniques used by Arab American stand-up comedians to distance themselves from their Arab origin and to ostracize Arabness.

In an interview, Dean Obeidallah, one of the founders of the Arab American Comedy Festival, says, "Jokes about Arabs being late, or smoking cigarettes, or fighting over the check - like these typical Arab things - get the biggest laughs in the show" (Amos). Arab names become again a source of humor when Obeidallah translates his Arabic surname into "Servant of Allah," which makes his situation even worse: "How hard would it be for me to make airline flights reservation for the rest of my life using that name? 'Hi, two tickets to Miami please. My name? Servant of Allah.' 'Hang on, let me transfer you to someone who can help you. Hello, FBI?"' (Amos). The joke again is misreading Obeidallah as an Arab and the laughter is created because of the fact that he is not, but unwillingly inherited an Arab name which is humorously ridiculed by him. Similarly, the source of Maysoon Zayid's punch lines is her parents whom she presents stereotypically in one of her performances. Zayid's father looks like Saddam Hussein, a typical Arab dictator for most Americans, and her mother looks like Haifa Wehbe, a famous Arab singer known for her sex appeal and exotic shows. Zayid presents herself as a funny Arab American stand-up comedian who is making fun of terrorist Arab men and exotic sexually provocative Arab women ("Maysoon Zayid"). In another performance, she compares the modern view of femininity and sexuality that she shares with her American peers with the Arab view of sexuality. She says, "You know, I am thirty years old and I am single, right, which is not a big deal because, like I said, it is like sex in the city. Whoo, I am so cool! Here is the problem, in Arab use I am actually 67" ("2008 New York Arab American Comedy Festival"). The punch line of Zayid's joke reiterates the stereotype of the patriarchal Arab world that looks at women as sex objects who become useless once they are older than thirty. Zayid sides with the American view of sexuality and ridicules the Arab culture, and in so doing presents herself and her Arab American identity as more American than Arab. 
Aron Kader, a Palestinian American stand-up comedian, not only reiterates a stereotype of the stupid Arab when he narrates the story of his trip to Amman to visit his cousin who always curses America in a funny Middle Eastern accent, but he also mocks religion to distance himself from that stupid Arab. He says:

(In an American accent) Well . . . you know . . . aaaaaa . . . I was over there after 9/11 and I was driving a cousin in Amman, Jordan . . . right . . . and I am driving around with my cousin who was like bitching and moaning about America . . . right ... (He converts his English into a middle eastern accent) "you son of a bitch America ... America think you so strong and powerful, so big and strong." Arabs love the cuss in English. They cuss their heads off in English. They won't do it in Arabic cuz then God could hear them ... you know. ("Aron Kader in Axis of Evil")

Dean Obeidallah also refers to religion when he imagines an Arab vampire who is afraid of pork rather than a cross: "How about an Arab Vampire? Instead of being afraid of a cross, he's afraid of pork. You hold it up. Haram. Bacon. Haram" (Amos).

In Ahmed's stand-up comedy routine about one of his visits to Dubai, religion is also a source of ridicule and laughter. Dubai, for Ahmed, is weird and schizophrenic "cuz you'll walk down to the beach and see a Muslim woman wearing hijab then you'll see European men in Speedos. You'll see a mosque and right across the street from the mosque there's a night club! So right around 8 o'clock every night all you hear is ... [Ahmed makes the sounds of call to prayer and a club beat]" ("Ahmed Ahmed"). In an American context, this would be explained as "multiculturalism," but in Dubai it is described as "schizophrenia." Ahmed presents himself as an American tourist confused about where to go: Should he pray in the mosque or drink in the club bar? He asks for God's help in words that violate a religious taboo, "Please God, help with your Arabic accent! Please." In Ahmed's view, Muslims in Dubai are hypocrites: "It's like you know you are a Muslim when you drink, gamble, have sex, but you won't eat pork! That's the weirdest thing, you won't eat pork." Religion also receives a share of ridicule connected to terrorism in Ahmed's performance. The Arab world is presented to be full of terrorist groups who compete for members. Organizations like Islamic 
Jihad, Hezbollah, Hamas, and Al-Qaeda have recruiters lined in front of mosques tempting Muslims to join them:

I think they have recruiters. These guys sitting outside of the mosque going up to these little Muslim boys, "Come here, come here, come here. I want to talk to you, come here. Don't go to al-Qaeda, they are shit. Come to the Islamic brotherhood. Why, you ask? Well, they only promise you 72 virgins. We will give you 72 virgins, one whore ... and a goat!" ("Ahmed Ahmed")

This kind of comedy is not self-deprecatory as many magazines' reviewers claim; it rather creates a dichotomy between the bad Arab and the friendly Arab American. The Arab world is presented to be an "other" for the Arab American performer. Ahmed creates this dichotomy when he compares himself with a terrorist who has the same name, but lives in the Middle East and speaks English with a Middle Eastern accent:

I googled my name and it matches the name of a guy in the Middle East who's a terrorist. I think he's in the Middle East googling me, going, [converts his English into an Arab accent] "There's this guy in America, man."

[Laughter]

People go up to him, "Hey man, you're so funny. Tell me a joke."

"I'm not a comedian! I'm a terrorist! Want me to prove it to you?

I'll blow myself up right now, I swear!” (“Ahmed Ahmed”)

Every time he imitates an Arab, Ahmed changes his American English into broken English and starts his sentences with "ehhhhhhh" to stress the difference between himself and Arabs:

I watch a lot of the news, man. I love watching the Middle Eastern people on the news talk about what's going on in the Middle East 'cuz all Middle Eastern people always start each sentence with, "ehhhh - ehhhh, the damn United States of America, they come into our country and they bomb our ... ehhhhhh.” (“Ahmed Ahmed")

Even governors in the Middle East speak English with funny Arab accents. Ahmed refers to the man who runs the city of Dubai as "amir." Although in Dubai he is referred to as a governor or a sheikh, the title "amir" sounds more Hollywoodish and exotic. The amir of Dubai is very 
proud of his seven-star hotel - one of a kind in the world - but when asked by critics about the institition which awarded the hotel seven stars, he answered stupidly in an Arab accent, "Ehhhh, I gave it seven stars, ehhhh" ("Ahmed Ahmed").

In performing their ethnicity, one may conclude, Arab American stand-up comedians try to carve an Arab American identity which is devoid of the western stereotypes of Arabs. However, in doing so, they do not demolish the stereotype but rather make it exclusively valid for Arabs who are made to be distant and different from Arab Americans. The comic license of stand-up comedy is used to reduce the impact of the Arab heritage on the Arab American identity, providing a new answer to the "who's who" question and re-mapping the relationship between the Arab, the American, and the Arab American. It is sort of identity alteration that dissociates them from their Arab diasporic origin and brings them closer to America. Instead of professing a hybrid identity and adopting a discourse that challenges a common culture which defines Arab America orientalistically, Arab Americans stage minstrelsy and, instead of being whites in black faces lampooning black people, they show Arab faces on stage lampooning Arab culture. In short, they verify their Arab American identity through disparaging their Arabness.

\section{Works Cited}

“Ahmed Ahmed.” YouTube, 19 Sept. 2010. Web. 15 Nov. 2013.

Aita, Judy. "Arab American Comics Use Laughter to Build Bridges: Fourth Annual New York Comedy Festival Enjoys Success." Allied Media Corp. Multicultural Communication, 20 Nov. 2006. Web. 10 Mar. 2013.

Alexander, Richard D. "Ostracism and Indirect Reciprocity: The Reproductive Significance of Humor." Ethology and Sociobiology 7 (1986): 253-270. Print.

Amos, Deborah. "But Seriously Folks, The Arab World is a Funny Place." NPR.org, 5 May 2011. Web. 22 May 2013.

“Aron Kader in Axis of Evil (Part1)." YouTube, 8 July 2009. Web. 20 Dec. 2013.

Brodie, Ian. "Stand-up Comedy as a Genre of Intimacy." Ethnologies 30.2 (2008): 153-80. Print.

Butcher, S. H., ed. The Poetics of Aristotle. New York: MacMillan, 1902. Print. 
Cullen, Frank, Florence Hackman, and Donald McNeilly. Vaudeville, Old and New: An Encyclopedia of Variety Performers in America. Vol. 1. New York: Routledge, 2006. Print.

Daube, Mathew. "Laughter in Revolt: Race, Ethnicity, and Identity in the Construction of Stand-Up Comedy." Diss. Stanford University, 2009. PQDT Open. Web. 21 Nov. 2013.

Freud, Sigmund. "Humor." The Standard Edition of the Complete Psychological Works of Sigmund Freud XXI. Trans. J. Strachey, et al. London: Hogarth P, 1961. 160-66. Print.

Hobbes, Thomas. Leviathan or the Matter, Forme, \& Power of a Commonwealth Ecclesiasticall and Civill. Ed. A.R. Waller. Cambridge: Cambridge UP, 1904. Print.

Kant, Immanuel. Critique of Judgment. Trans. Werner S. Pluhar. Indiana: Hacket, 1987. Print.

Limon, John. Stand-up Comedy in Theory, or, Abjection in America. Durham: Duke UP, 2000. Print.

Marks, Alexandra. "Get Your Arab On': Comedians Chip Away at Ethnic Fears.” The Christian Science Monitor 14 Nov. 2006. Web. 15 Nov. 2013.

"Maysoon Zayid Performs at ATFP Fifth Annual Gala." YouTube. ATFP, 26 Oct. 2010. Web. 15 Feb. 2014.

McIlvenny, Paul, Sari Mettovaara, and Ritva Tapio. "I Really Wanna Make You Laugh: Stand-Up Comedy and Audience Response." Folia, Fennistica and Linguistica: Proceedings of the Annual Finnish Linguistics Symposium. Ed. Matti K. Suojanen and Auli Kulkki-Nieminen. Tampere University Finnish and General Linguistics Department Publications, 1993. 225-47. Print.

Mintz, Lawrence E. "Stand-up Comedy as Social and Cultural Meditation." American Quarterly 37.1 (1985): 71-80. Print.

"2008 New York Arab American Comedy Festival Stand Up Preview." YouTube, 22 Dec. 2007. Web. 23 Nov. 2013.

Parker, Bethany. "Probing Question: What are the Roots of Stand-up Comedy?" Penn State 12 Sept. 2008. Web. 17 Dec. 2013.

Ramachandran, V.S, and Sandra Blakeslee. Phantoms in the Brain: Probing the Mysteries of the Human Mind. New York: Harper, 1999. Print.

Salama, Vivian. "Stand-up Diplomacy." Forward Magazine 1 Feb. 2008. Web. 20 Dec. 2013.

Sjobohm, Juan. "Stand-Up Comedy around the World: Americanization and the Role of Globalized Media." Malmö University Electronic Publishing. Malmö högskola/Konst, kultur, kommunikation, K3, 2008. Web. 18 Oct. 2013.

Spencer, Herbert. "The Physiology of Laughter." The Bibliophile Library of Literature, Art, and Rare Manuscripts-History, Biography, Science, Poetry, Fiction, and Rare and Little-known Literature from the Archives of the Great Libraries of the World. Vol XXII. Ed. Nathan Haskell Dole, Forrest Morgan, and Caroline Ticknor. New York: International Bibliophile Society, 1904. 7561-72. Print. 
"Stand-up." Merriam Webster. An Encyclopedia Britannica Company. 11 Oct. 2013. Web. 5 Jan. 2013.

"Stand-Up Comedy: Arab American Comedians in New York (Legendado)." ajmantube.com, 7 June 2012. Web. 10 Nov. 2013. 